\title{
EXPRESSANDO-SE NA LÍNGUA DO ANTÍPODA: FANTASIA NIPO- BRASILEIRA ACERCA DA ORIGEM DAS LÍNGUAS ${ }^{1}$
}

Shuhei Hosokawa

A língua tupi nunca foi objeto de estudos rigorosos no Brasil.

- Arthur Neiva, Estudos da Língua Nacional

Tupão, tupi

Não sei que mais

Já me esqueci de onde sou

- de "Brasileiro em Tóquio", letra de Pedro Luís e A Parede

E imaginar uma língua significa imaginar uma forma de vida.

- Ludwig Wittgenstein, Philosophical Investigations

1. Nota do Tradutor: $O$ presente artigo foi primeiramente publicado em inglês no livro intitulado Searching for Home Abroad - Japanese Brazilians and Transnationalism, editado por Jeffrey Lesser, que é também autor da introdução e do primeiro texto, pela Duke University Press, Durham \& London, em 2003, pp.21-46. Nota do Autor: Gostaria de agradecer ao Senhor Katsunori Wakisaka, genro de Kôyama, por ter-me fornecido informações pessoais importantes sobre o autor e suas publicações particulares.

2. Professor doutor da International Research Center for Japanese Studies. 
A origem da língua é uma questão intimidadora para os lingüistas modernos. Isso não significa, entretanto, que tal problema tenha desaparecido de discussões contemporâneas; permanece ainda um tema comum em conhecidos estudos científicos. Isto é particularmente verdade no Japão, onde o discurso da origem da língua nacional é tão popular que "não se pode pegar, a esmo, um diário ou um semanário sem encontrar algum artigo (...) 'anunciando' a 'descoberta' de que a língua japonesa está geneticamente relacionada com este ou aquela língua, geralmente alguma cuja posição geográfica do Japão é tão remota quanto a probabilidade de que tenha algo a ver com os japoneses" (Miller, 1980, 18). A obsessão com as origens de que trata o lingüista Andrew Miller pode advir da influência decisiva de nihongo (língua japonesa) na identidade nacional japonesa - a nação é essencialmente monolíngüe e sua língua é utilizada em apenas um país. A popularidade do discurso das origens da língua japonesa certamente deriva da equação raça, território e língua entre a população japonesa.

Quando se busca as origens "perdidas" de uma língua, não se pode evitar adentrar nos domínios da imaginação mítica e utópica nascida da ideologia circunstancial de raça, nação, geografia, história, religião, literatura, e, é claro, língua. O crítico literário japonês Osamu Murai enfatiza as implicações expansionistas no discurso da origem da língua e da raça japonesas, que "mostram traços visíveis da invasão da Ásia pelo Japão moderno (...). $\mathrm{O}$ discurso sobre a sagrada e longínqua 'origem do japonês' desempenha um papel de acobertar a invasão e a dominação colonial do verdadeiro Japão $(1993,156)$. Para Murai, o interminável debate entre as hipóteses do "norte" (a de que os japoneses teriam vindo da Melanésia ou da Índia subcontinental) e do "sul" (a de que os japoneses vieram da Sibéria ou da Mongólia) nada mais é do que uma transposição epistemológica do eixo Leste-Oeste, um relacionamento que é historicamente mais duradouro e ideologicamente mais hierárquico. $\mathrm{O}$ eixo sul-norte "apaga o Outro" do Oeste para assegurar a identidade japonesa (ibid., 158; veja-se também Murai 1992). Em outras palavras, posicionando o sul e o norte como locais de origem, o nacionalismo japonês não apenas romantiza o antigo e o exótico como também justifica a integração política de Okinawa e Hokkaido, ilhas do sudeste e do nordeste que foram integradas como territórios pelo governo nos anos de 1870. Naturalmente, o discurso sobre a origem da língua japonesa assevera o eixo norte-sul, na medida em que "identificação de língua e raça" é assumida: o japoneses-ur teriam vindo com sua língua japonesa-ur (Miller, 1977, cap. 6).

Rokurô Kôyama, entretanto, defende que a língua japonesa e uma língua ameríndia aparentemente não relacionada, o tupi, teriam se originado de uma mesma fonte polinésia comum. Visto que Kôyama era um imigrante japonês no Brasil, a explicação para tal não é tão simples, já que as condições políticas, históricas e sociais que rodeiam a produção textual da teoria não foram as mesmas de outros estudos sobre a língua. O objetivo de Kôyama era singular: concentrou-se menos na origem da língua e da raça japonesas do que na mitificação da origem de uma minoria étnica ao autenticar a língua no interior da ideologia nacional brasileira. Isto torna seu trabalho distintivo 
entre a literatura abundante sobre as origens da língua japonesa e sobre a tupinologia. De acordo com o lingüista de tupi, Wolf Dietrich, "Experiências no campo das línguas indo-européias têm mostrado que a reconstrução de uma única protolíngua é não só uma construção hipotética, como pode nunca ter sido uma realidade histórica (a990, $7-8 n .2)$. Se isto for acurado, a "realidade mitológica" de Kôyama em procurar uma língua Proto-Tupi-Japonesa merece ser examinada.

Kôyama ficou obcecado com a língua indígena tupi em parte por causa do monolingüismo da tradição nativa japonesa. Falar apenas uma língua era, e é, comum no contexto da pátria japonesa, mas, com a imigração, os viajantes terminam por reconhecer seu isolamento lingüístico. Ser monolíngüe é admitir um contato/contrato unilateral: os imigrantes japoneses podiam falar, mas as sociedades fora do Japão não podiam escutá-los. Língua, assim como fisionomia, era determinante para a identidade étnica de um issei no Brasil. Se não fosse pela barreira da língua, um tipo de exílio lingüístico, Kôyama não teria necessitado do tupi. Portanto, o monolingüismo ao mesmo tempo restringiu e possibilitou sua vida e imaginação, e seus textos sugerem uma tensão existencial que o pressionava a redefinir sua identidade hifenada. Sua noção de língua tupi-japonesa proporcionou uma narrativa de origem e ancorou a posição duplamente marginalizada de sua comunidade tanto no Japão quanto no Brasil.

O modelo dominante da nação brasileira é a de miscigenação de três raças - de africanos, europeus e índios. Os tupis, parte de um grande grupo na parte centro-oeste do Brasil, foram quase que completamente dizimados pelos europeus durante o período colonial. Ironicamente, os tupis se tornaram um símbolo evocativo do nativismo brasileiro que se inicia no século XVI, quando a similaridade oral acidental de algumas palavras portuguesas e tupis foi interpretada pelos missionários como um sinal justificador para o catecismo (Geipel, 1993, 13). Mais recentemente tais noções reapareceram em canções pop contemporâneas como "Festa da Música" (Gabriel O Pensador) e "Tubitupy" (Lenine). O modelo Africano/Europeu/Tupi foi cuidadosamente confeccionado pelas elites brasileiras e prevalecia por longo tempo antes que os japoneses ali se estabelecessem, no início do século XX.

A preocupação de Kôyama era sobre como "recém-chegados" como os imigrantes japoneses se tornariam uma parte legítima da nação brasileira. Convencido da importância da etimologia, articulou uma dupla identidade através de uma interação intrincada entre as identidades nacional japonesa e étnica nipo-brasileira, construindo da autocategorização dual de ser tanto japonês quanto brasileiro ao estabelecer os povos indígenas como brasileiros $e$ japoneses, como ancestrais nacionais $e$ étnicos. ${ }^{3}$

3. A noção de "étnico" é dificil de ser compreendida pelos japoneses, pois para eles a palavra minzoku é designada para significar tanto "nação" quanto "unidade étnica", mesmo em textos acadêmicos (Tanaka, 1999, 175-76). Essa tradução polissêmica da palavra minzoku pelos intelectuais do periodo Meiji na metade do século XIX pode refletir as circunstâncias nacionalistas em que a etnologia, a antropologia e os estudos folclóricos foram estabelecidos. A dualidade das categorias "nacional" e "étnico" é também discutida em Hosokawa, 1999. 
Rokurô Kôyama (1886, Kumamoto - 1976, São Paulo) imigrou ao Brasil em 1908, como um dos quatro intérpretes (ele havia estudado espanhol) a bordo do Kasato Maru, o primeiro navio que trouxe imigrantes japoneses ao Brasil. Era conhecido como o "pai do jornalismo nikkei" por ter sido responsável por um jornal mimeografado no Kasato Maru. Em 1921, estabeleceu um jornal chamado Seishû Shinpô (Semanário de São Paulo) em Bauru, uma pequena cidade no estado de São Paulo. O jornal continuou até 1941, quando o governo proibiu a publicação de periódicos em línguas estrangeiras. Em 1935, Kôyama mudou-se para a cidade de São Paulo, capital do estado, liderou um círculo amador de escritores de haiku, e publicou três antologias privadas depois da II Guerra Mundial.

De acordo com suas memórias póstumas, Kôyama se tornou interessado no "povo primitivo que parece[ia] com os japoneses" em seu segundo dia no Brasil, quando um outro intérprete, que estivera no Brasil por vários anos, tentou sossegar seus compatriotas ansiosos no trem vindos do porto, contando-lhes de modo jocoso sobre uma tribo estranha de nativos brasileiros chamados Tupi. Kôyama, pensando se aqueles "primitivos" falariam a língua japonesa, teve uma visão de um homem nu acocorado numa enorme rocha ao longo da estrada de ferro. Aquele momento dramático o levou a querer tanto a viver no Brasil quanto a estudar a cultura tupi (Kôyama, 1976, 435-40). Se fíccional ou não, tal proximidade com uma tribo imaginada influenciou seus três livros acerca dos tupis: $O$ Léxico Tupi (1951) e Investigação sobre o Significado-Sentido de Cada Silaba na Composição da Língua Verbal Humana Através do Significado Original da Língua Tupi Nhem (1970, vol. 1; 1973, vol. 2).

O ponto de partida de Kôyama em transformar o japonês em tupi foi a semelhança física entre os dois povos. "As feições dos nativos tupi-guaranis são exatamente as mesmas que as nossas, que somos japoneses. Desde a primeira vez que os vi, não pude esquecê-los. Quanto mais olho para eles, mais encontro semelhanças. Quando nos encontramos e nos relacionamos, sorrimos uns aos outros mais pacificamente do que para os europeus. Será que os japoneses e os tupi-guaranis originariamente vieram da mesma semente polinésia? Será que nos encontramos de novo após quatrocentos anos? Será que a língua dos nativos tupi-guaranis era a mesma que a dos japoneses antigos?" $(1951,1) \cdot{ }^{4}$ Nessa passagem a fantasia de Kôyama cruza espaços geográficos e históricos. O tupi, uma raça irmã do Japão, esperou pela vinda da família de longe, e os japoneses então chegavam à terra de seus irmãos. Tal empatia é crucial para esta história imaginária. A distância espacial entre os remotos asiáticos e a arcaica população indígena é justaposta à temporal. O fato de que a definição de tupi é "ancestral"

4. Todas as traduções são do autor. [N. do T.: Hosokawa traduz para o inglês as citações aqui incluídas.] 
convenceu Kôyama da relação mitológica entre as duas raças. Kôyama também traduziu tupi como "pai supremo" em O Léxico Tupi, tornando assim o caminho associativo entre os japoneses e os tupis mais suave. Baseando-se no respeito tupi pelos ancestrais, como se evidencia por sua auto-identificação, ele habilmente associa-a com o sistema de crença folclórica dos japoneses em venerar a ancestralidade que forma a base do xintoísmo, a religião nacional japonesa.

\section{Imaginação Léxica: Toponímia e Romantismo Tardio}

O primeiro trabalho tupi de Kôyama, $O$ Léxico Tupi, contém aproximadamente 2.500 palavras $^{5}$ Embora Kôyama não torne explícito seu critério para a seleção, muitos dos verbetes estão relacionados com a natureza; uma centena de minerais, noventa plantas, setenta relativas à água, cinqüenta peixes, cinqüenta animais, quarenta insetos, quarenta relativas à floresta. Kôyama, como aqueles autores listados na bibliografia de seu Léxico, tende a enfatizar a natureza na vida dos tupis. Sua equação entre primitivismo e natureza pressupõe uma equação paralela entre civilização e cultura. Kôyama também inclui um número relativamente grande de topônimos (pelo menos cinqüenta). Bauru, o nome da cidade onde viveu por dez anos, significa "rio barrento" Ao relacionar um lugar singular (Bauru) com um significado mais geral (rio barrento), ele usou a geografia brasileira sob uma compreensão tupi para desvelar, por assim dizer, um Brasil virtual cujo passado pré-datava a "descoberta" de Cabral em mil anos. Tais topônimos eram designados para encorajar os falantes de japonês, leitores de $O$ Léxico Tupi, a ver a terra que eles habitavam como lhes sendo familiar. De

5. Kôyama consultou as seguintes referências (Kôyama, 1951, 3-4): Padre Antonio Ruiz de Montoya, Vocabulario y Arte y Tesoro: Guarany (ou Tupi) - Español (1639); Plinio Ayrosa, Primeiras Noções de Tupy (1933); Baptista de Castro, Vocabulario Tupy-Guarany (1936); Theodoro Sampaio, O Tupi na Geographia Nacional; Diccionario Gurany-Castellano (1901); P. H. Cuash [P. Antonio Guasch], Diccionario Castellano-Guaraní y Guaraní-Castellano [sem data]; Affonso Antônio de Freitas, "Os Guayanas de Piratininga”, Etnografia Paulista (1910); Alfredo d'Éscragnole [Afonso de Escragnolle] Taunay, Os Índios Caingangs: Monographia [sem data]; Angionet [Angyone] Costa (1934), Introdução à Arqueologia Brasileira: Etnografia e História, Biblioteca Pedagógica Brasileira, Editora Brasiliana, séries 5, vol. 34; Paul Rivet, As Origems [sic] do Homem Americano, Instituto Progresso Editorial. Entre essas dez referências, pude consultar somente cinco (Ayrosa, Sampaio, Guasch, Costa e a edição francesa original de Rivet). Embora eu admita que minha reconstrução da tupinclogia de Kôyama seja muito incompleta, a contribuição dos livros que não pude consultar deve ser significativa. Entre todos os verbetes no O Léxico Tupi derivam ou das Primeiras Noções de Tupi de P. Ayrosa ou de O Tupí na Geographia Nacional de Theodoro Sampaio. A informação de dois dicionários de guarani-castelhano não consultados deve ter sido minimamente incorporada no trabalho de Kôyama como o dicionário de Guasch. "Os Guayanas de Piratininga" de Affonso Antônio de Freitas não deve ter sido incorporado no texto de Kôyama, pelo que considerei de sua discussão sobre o mesmo tema encontrada em seu Vocabulário Nheengatú (1936, 43-44). Sobre a filologia tupi, veja-se também Ayrosa, 1967, e Chermont de Miranda, 1946. Kôyama usou "tupi" e "tupi-guarani" como sinônimos. Tupi não é uma língua, mas uma variante do guarani, uma língua nativa do Paraguai. 
acordo com uma das referências primárias de Kôyama, O Tupi na Geographia Nacional de Theodoro Sampaio, "Em tupi, os nomes dos locais são usualmente frases completas que traduzem uma idéia, um episódio, uma feição característica dos lugares aos quais se aplicam; eles são, enfim, verdadeiras definições de um meio local" (1928, ii). Para Sampaio, a inteligibilidade comum dos topônimos desde o tempo em que o tupi era falado no estado de São Paulo (por volta dos séculos XVII e XVIII) estava tão perdida que eles haviam se tornado "verdadeiros enigmas" Reconstrução semântica de nomes de lugares "fossilizados ou cruelmente adulterados" - através de técnicas que incluíam ortografia e ortoepia - constituía-se, portanto, como uma "salvação de um monumento histórico" (ibid., xxxiv).

Tal visão histórica de como recuperar o passado através do conhecimento de topônimos significativos conferiu certa legitimidade à história do território presentemente chamado Brasil. Sampaio e outros tupinólogos de início do século XX viam as línguas ameríndias como evidência histórica da transação entre nativos (que ofereciam o significado-sonoro) e colonizadores (que a imortalizaram através do sistema gráfico). O povo tupi estava quase extinto no Brasil de Sampaio (e de Kôyama), mas sua cultura ainda estava presente, sobrevivendo na forma de nomenclatura. Essa é a razão pela qual os tupinologistas privilegiavam lexicografia e filologia mais que a morfologia e a fonologia ${ }^{6}$. Está claro que Kôyama fazia parte dessa tradição intelectual quando ele aponta "Embora hoje em dia no Brasil muitos poucos falem tupi ou guarani, com exceção dos primitivos puros, a língua tupi vive nos nomes das cidades, das vilas, em todos os locais nos estados brasileiros. Tupi [a língua] vive em todos os locais em um terço dos nomes das estações de trem no Brasil. Tupi vive em nomes de locais, na vida diária dos brasileiros, nos nomes das coisas, de animal de plantas, de montanhas, rios e campos. Tupi vive especialmente de modo belo, doce e brilhante nos nomes das mulheres brasileiras" $(1951,14)$. O conhecimento e a imagem que Kôyama tinha do tupi era do tipo romântico tardio - ele adotou o conceito do "bom selvagem", comum entre os tupinólogos, que é contemporaneamente rejeitado pelos etnólogos. Os autores românticos brasileiros no século XIX não eram mais missionários e viajantes que tinham contato direto com os povos indígenas, mas antes "historiadores" que citavam os escritos daqueles pioneiros e, mais importantemente, tinham como meta "alimentar o espírito do nacionalismo" (discurso de Francisco Adolpho de Varnhagen em 1840, apud Haberly 1983, 17) através da autenticação de uma cultura nativa quase extinta. Nas palavras de Plínio Ayrosa, "Toda palavra ou frase tupi tem uma tradução forçosamente espontânea, clara, fácil e lógica [numa língua civilizada como a portuguesa]. Se não é imediatamente compreendida, é porque a palavra foi adulterada pelo uso após séculos ou está mal-escrita" $(1933,99)$.

$O$ romantismo é constitutivo do nacionalismo, uma posição tomada por Theodoro Sampaio, outro autor significativo para Kôyama. "Quero ver o amor dos brasileiros pelo

6. Uma exceção interessante foi Mário de Andrade, para quem a nasalização do português no Brasil foi uma influência do tupi (1991). 
passado de sua terra e o desejo de conhecer e demonstrar estima por aquilo que eles herdaram dos primitivos habitantes, os donos do país (...). Isto é sentimento nacionalista (...). É possível que a raça americana, embora derrotada, não perca tudo. Se no sangue dos descendentes a dosagem diminui até ser extinta, a memória dos habitantes primitivos não será perdida enquanto os nomes de lugares sobreviverem onde a civilização mostra seu triunfo" (Sampaio, 1928, i-ii). Este tipo de visão nostálgica, que ignora os sacrifícios sangrentos feitos pelos "habitantes primitivos" conduz à redução da cultura indígena a um índice para uma "geografia nacional" Acusando certos autores jesuítas de sugerir que o tupi e seus inimigos são geneticamente equivalentes, Sampaio distingue o bom selvagem do selvagem ignóbil: "Histórica e etnograficamente, o tupi é um grupo étnico, que fala uma língua na América do Sul, e é um grupo que não deve ser confundido com outros muito diferentes, nem com línguas diferentes comumente chamadas tapuias. O nome tupi pode ser, deste ponto de vista, um nome nacional. Isto jamais será verdade em relação aos tapuias. Os tupis foram uma grande nação com sua língua própria. Este não é o caso dos tapuias, que não são nem nação, nem língua (ibid., ix.; grifo meu).

Nessas citações, a idéia do bom selvagem tem realmente uma concepção romântica de nação (uma língua, uma cultura). Tupi, reconhecido como um grupo nacional, torna-se o nome-campeão para os nativos brasileiros. A nacionalização do selvagem é um conceito romântico do nacionalismo brasileiro (veja-se também Freitas, 1936, 3237, 52-57; Burns, 1968, caps. 3-6).

\section{Pastoral sob Pressão Étnica}

Seria de alguma valia situar o trabalho de Kôyama nesta tradição romântica? Certamente existem diferenças importantes entre os autores brasileiros e os jornalistas japoneses. Para os primeiros, a questão tupi centra-se em como os povos indígenas podem contribuir para a construção de uma identidade nacional entre a mistura heterogênea do povo brasileiro por meio de uma conversão do passado histórico em um mito autenticado. Os tupis são "aglutinantes" em termos de ideologia porque se tornaram um cimento invisível, um denominador comum para aquilo que os brasileiros pensam sobre seu passado nacional.

Kôyama, ao contrário, apela para os tupis em termos de uma legitimidade racial e cultural dos japoneses como parte da nação brasileira. "Tornar-se brasileiro" não é fácil para pessoas de fisionomias asiáticas, mesmo num país entusiasta da democracia racial $^{7}$ Kôyama celebra a igualdade racial do Brasil como se tal afirmação fosse um

7. Os sociólogos em sua maior parte duvidam mais que afirmam a igualdade racial brasileira (veja-se Andrews, 1991; Bastide e Fernandes, 1959; Fernandes, 1972; Fontaine, 1985; Hellwig, 1992; Skidmore, 1973; Winant, 1994). Problemas "raciais" no Brasil são predominantemente conceituados entre os espectros de brancos e negros. Os grupos indígenas e asiáticos são postos sob uma categoria diferente: friç̧ão étnica (Lesser, 1999, 10-11). 
passaporte para os imigrantes se tornarem cidadãos brasileiros. Se os tupis eram reconhecidos como constituintes da nação brasileira, sua raça irmã a princípio se tornaria verdadeiramente brasileira. O que está em jogo é o laço imaginário com os japoneses que se evidencia pela aparência física e se certifica pela compatibilidade lingüística. Entre as muitas virtudes da cultura tupi, admirava especialmente sua "sociedade verdadeiramente comunitária e coletiva" (Kôyama, 1951, 8). Aprender a língua de tal tribo pacífica envolveu um aprendizado sobre sua nobre alma. Assim imaginou ele sua vida idílica: "Os nativos acordavam cedo todas as manhãs. A primeira coisa que faziam era se banharem num riacho próximo. Depois do café da manhã iam trabalhar: na roça, pesca, caça, e provendo de alimentos a sociedade tribal. As mulheres trabalhavam em casa. De noite, o povo se juntava ao redor de uma fogueira. Era costume que os mais velhos da oca [casa ou lar, em tupi] contar [histórias] aos homens jovens que tomavam conta do fogo" (ibid., 8). Esta passagem baseia-se em idéias de Introdução à Arqueologia Brasileira de Angyone Costa $(1934,255)$, mas Kôyama acrescentou duas invenções: a ocupação exclusiva das mulheres em trabalhos domésticos e a reunião familiar em volta da fogueira a contar histórias. Estas duas alterações da ilustração de Costa evocam a vida idealizada dos imigrantes japoneses em fronteiras selvagens. Na época em que $O$ Léxico Tupi foi publicado, em 1951, muitos japoneses viviam em cidades e subúrbios longínquos das fronteiras. A vida de fronteira que Kôyama representou, então, evidencia nostalgia.

A idealização da vida tupi por Kôyama o levou a omitir de $O$ Léxico Tupi uma prática que todos os outros autores que haviam estudado a vida indígena brasileira incluíram desde o século XVI: a antropofagia. Embora esteja claramente mencionada pelos autores que consultou (Ayrosa, 1933, 22; Costa, 1934, 264), Kôyama relutou em repassar tal informação a seus leitores. Evidentemente, um "léxico" enquanto uma forma textual não necessita de precisão etnográfica, mas negligenciar tal prática notória pode indicar a ênfase não intencional de Kôyama em uma imagem bucólica dos tupis. Em resumo, ele tomou da tupinologia apenas o que se relaciona com a visão nostálgica de uma selvageria tupi a fim de consolidar a afinidade entre os tupis e os imigrantes japoneses nas fronteiras.

É provável que a imagem comunal em $O$ Léxico Tupi esteve profundamente relacionada a questões que envolviam a população de imigrantes japoneses em fins dos anos 1940, mais do que com a simples adoção do clichê do bom selvagem. Os anos imediatamente após a II Guerra Mundial no Brasil foram de conflitos comunais entre os que acreditavam na vitória do Japão na guerra do Pacífico (kachigumi, ou "vitoristas") e os que reconheciam sua derrota (makegumi, ou "derrotistas"). Seu antagonismo alcançou o pico em 1946 e 1947, quando mais de vinte makegumi foram assassinados pela facção militantes dos kachigumi.

Tal conflito aterrorizador e seu trauma "étnico" resultante foram críticos para a transformação da identidade. A expressão "imigrados japoneses no exterior" se tornou sinônimo de "nipo-brasileiros" porque a confusão envolveu praticamente todos os imigrantes e suas famílias no Brasil. Os imigrantes japoneses começaram a pensar 
menos em retornar ao Japão e mais em tomar residência permanente no Brasil. Começaram a se definir como ancestrais de cidadãos brasileiros ao invés de imigrados japoneses. Os esforços pós-guerra para a assimilação começaram com a mudança na autoatribuição étnica como nipo-brasileiros. Essa auto-categorização hifenada foi também chamada koronia, tomada de empréstimo da palavra portuguesa colônia, que integrou a fala dos imigrantes pelos fins dos anos 1940 . O uso do termo em língua portuguesa indica o início de uma nova identidade assimilativa da geração de falantes do japonês.

Tal situação pós-guerra da comunidade de brasileiros de origem japonesa coincidiu com a conceituação e a finalização de $O$ Léxico Tupi. Kôyama, um simpatizante do makegumi e um dos primeiros imigrantes a clamar pelo direito de residência permanente no Brasil, preocupava-se com o impacto de circunstâncias sociopolíticas na comunidade brasileira de origem japonesa, e tal envolvimento subjaz em suas generosas intenções no prefácio de seu léxico: "Se as pessoas entenderem, falarem e ouvirem sua língua nativa, terão sentimento poético e senso de humor, e conseqüentemente seus corações se atenuarão. Publiquei, assim, este livro, especialmente para os nipobrasileiros" (5, grifo meu). O Léxico Tupi, pois, não é simplesmente diletantismo; é um convite para acalmar tensão étnica e para unir os japoneses no Brasil através de "sentimento poético e senso de humor"

\section{Da Gramática à Intuição}

As páginas finais de $O$ Léxico Tupi tratam de uma gramática concisa. Embora esta parte inclua irrelevâncias do ponto de vista lingüístico (por exemplo, Kôyama, apoiando-se principalmente no trabalho de Ayrosa, menciona partes da fala em português, tais como artigo, como sendo ausentes tanto do idioma japonês quanto do tupi), é importante em termos de aprofundar fantasias lingüísticas.

A única contribuição original de Kôyama na gramática encontra-se em sua associação de palavras compostas com a composição de ideogramas japoneses (e chineses). Com o neologismo kongengo, ele identifica "palavras-originárias-em-radicais": vários mono ou dissílabos básicos que designam elementos como água, pedra, pessoa e animal (sobre substantivos compostos, veja-se Ayrosa, 1933, 45-45; Sampaio, 1928, $1920,137-38)$. Por exemplo, ita (pedra) + oca (casa) = itaoca (caverna); pira (peixe) + juba (ouro) $=$ pirajuba $($ peixe dourado).

Muitos ideogramas japoneses têm construções semânticas similares que se baseiam na combinação dos elementos da esquerda (hen) e da direita (tsukuri). Por exemplo, um hen que designa a "pessoa" + um tsukuri que designa um "senhor" = morar. A estrutura da letra para "morar", então, implica que morar ou habitar significa ser uma pessoa-senhorio no espaço ocupado. Poder-se-ia comparar esta exegese gramatológica de ideogramas sino-japoneses a palavras compostas em línguas européias. Como os hen referem elementos como seres humanos, árvores, peixe, terra, e água, Kôyama concluiu que "o tupi expressa pelos sons o que os hen dos ideogramas japoneses designam [de palavras-originárias-em-radicais]" (Kôyama, 1951, 121). Hen em si 
mesmo não é pronunciado. Portanto, palavras-originárias-em-radicais, ou sons sem forma gráfica, podem ser vistas como complementarias ao hen, ou gráfica sem sons. Kôyama desta forma demonstrou certa afinidade lingüística entre duas línguas aparentemente incomensuráveis.

Este passo gigante de uma língua não letrada ao grafismo do antípoda implicou para Kôyama que os japoneses e os tupis talvez tivessem percebido o mundo de modos similares. Sua conviç̧ão foi reforçada por um número de palavras tupis cujos sons ele acreditava corresponder à semântica e/ou fonética japonesa: tori ("uma espécie de pássaro" em tupi e "pássaro" em japonês); e ura ("verme" em tupi, e "avesso" ou "águas rasas" em japonês). Até alguns topônimos japoneses parecem ter sentido em tupi: Tiba (Chiba) significa "zona" em tupi, enquanto Kamakura (uma capital medieval) pode referir kamarua em tupi (peito exposto). Neste caso, não havia nenhuma relação entre os significados das palavras em tupi e em japonês. Ao contrário, Kôyama se impressionou com o fato de que alguns arranjos fonéticos em tupi soavam como japonês. Este ensaio demonstrará que, enquanto se aprofundava em seu estudo de tupi, Kôyama se convenceu da causalidade, não da coincidência, entre a fonética tupi e a semântica japonesa. "Traduzindo a língua indígena tupi através do português para o japonês, descobri muitas palavras tupis cujos sons e significados são exatamente os mesmos que em japonês (...), imagino que quando se fizer um estudo comparativo das palavras antigas do tupi e do japonês que ainda sobrevivem em dialetos locais, certamente descobriremos muitas palavras polinésias" (Kôyama, 1951, 135).

A pesar de tais conexões, Kôyama nunca se sentiu completamente satisfeito com O Léxico Tupi, pois dependeu de livros em português e, como resultado, deixou de demonstrar uma relação imediata do tupi com o japonês: "As duas línguas se assemelham intimamente. Mesmo assim é dificil concluir que os índios e os japoneses se parecem lingüisticamente tanto quanto o são fisicamente" (ibid., I; grifo meu). A tarefa de toda a vida de Kôyama foi revelar uma semelhança lingüística entre as duas línguas que devesse, por sua vez, comprovar aquela mais óbvia, fisionômica. A demonstração de uma ligação biológica e lingüística com o povo indígena, portanto, legitimaria tanto a presença japonesa no território brasileiro quanto sua inclusão na nação brasileira. Uma posição tal não era aceita amplamente já que a aparência "oriental" dos imigrantes japoneses e seus descendentes há muito traíam seus esforços de assimilação com a sociedade dominante brasileira, porque "fisionomia em geral permite uma categorização instantânea" (Lesser, 1999, 169; veja-se também 15, 108). O rótulo social japonês lhes era dado pela sociedade brasileira, não era escolhido pelos imigrantes ou seus descendentes. Assim, uma fisionomia com "preço fixo" se tornou negociável no sentido em que criava uma âncora visível para se tornar brasileiro. Levados pela convicção de que povos similares falam em línguas similares, Kôyama tentou encontrar uma correspondência lexical ipsis litteris entre as duas línguas. 


\section{Momento de Epifania}

Vinte anos depois da publicação de $O$ Léxico Tupi, Kôyama tomou uma atitude muito mais desafiadora em relação à lingüística moderna, que tratava, assim acreditava ele, apenas de explicações mecânicas. "Quanto à lingüística e gramática japonesa, sou completamente ignorante e diletante. Sou também um completo estrangeiro da lingüística ocidental e das leis fonéticas e não tenho nenhuma sensibilidade para elas" (Kôyama, 1970, 4). Seu uso de nhem ("língua" em tupi) em seu novo trabalho - que teve o mistificador título Investigação do Sentido-Significado de Cada Silaba na Composição da Lingua Humana Verbal através do Significado Original da Lingua Tupi Nhem - em oposição ao uso do tupi-go ("língua tupi" em japonês) no $O$ Léxico Tupi, mostra seu ponto de vista propositadamente "êmico" Qual foi seu método alternativo?

"Meu método assim se explica. Não classifico [as palavras] como substantivos, pronomes, verbos, verbos auxiliares, advérbios, etc. A lingüística e a fonologia ocidental não existiam dez mil anos atrás [quando o tupi era usado], e creio que a lingüística japonesa foi criada apenas há duzentos anos, através da imitação ocidentalizada. Qual o sentido em comparar a língua não-letrada nhem e o japonês de acordo com tais leis [lingüísticas]? Pretendo analisar nhem sem nenhuma aplicação de qualquer lei lingüística ocidental. Não me apoio em gramáticas portuguesas ou em qualquer pesquisa. Inicio minha pesquisa tomando as palavras que compartilham de mesmos sons e significados em nhem e japonês." (Kôyama, 1970, 4)

Fechem os livros, aconselha ele, para ouvir os sons de nhem e sentir a correspondência básica entre som e sentido. Nhem é a mesma língua que seus ancestrais falavam em sua vida de caça e coleta, há milhares de anos. Existe uma combinação de som e significado que subjaz no japonês contemporâneo. Em termos simples, a arqueologia de Kôyama presume que: (1) existiam povos Ur-Japonês-Tupi na Polinésia; (1) milhares de anos atrás eles se mudaram para o Japão e para o Brasil; e (3) os que se mudaram para o Japão se tornaram letrados e civilizados e esqueceram-se de sua língua original, enquanto os que migraram ao Brasil mantiveram sua cultura original. Várias teorias de tais migrações humanas de larga escala eram parte dos primeiros esforços da antropologia natural para descobrir o eterno enigma da origem do homo sapiens. Um dos livros na biblioteca de Kôyama confirma a teoria Tupi-Polinésia: "O Pacífico nunca foi um obstáculo [para o fluxo humano], mas foi, ao contrário, um laço entre a Ásia e a Oceania e o Novo Mundo (...). O Novo Mundo foi desde a era préhistórica um centro de convergência de raças e povos" (Rivet 1957, 173). A Polinésia é, assim, colocada como um berço dos tupis e dos japoneses pela tupinologia de Kôyama (veja-se Yaguello, 1991, 22).

Entretanto, como Kôyama teria se convencido de tal conexão polinésia? O momento da revelação veio quando começou a questionar porque iko (vamos!) em tupi 
significava o mesmo em japonês. O dicionário tupi-japonês diz que $i$ em tupi significa "água" ou "pequeno", enquanto ko designa "aqui", "bater", "pisar forte", "esmagar", "abrigar", "crescer", "manter", "nutrição aos sedentos" Combinando dois significados de $i$ e nove de $k o$ resulta em dezoito possíveis significados de $i k o$ : água-aqui, bater em água, pisar forte na água, crescer água, manter água. A inspiração corria no corpo de Kôyama.

"Estava perdido [sobre o que pensar sobre o significado de iko]. É um sentidopelo-som [onkan, neologismo de Kôyama] advindo de tal sentimento de necessidade [na vida diária]? De repente, percebi o significado de $i k o$ [vamos!] pela primeira vez, pois a palavra lembrava-me de minha própria vida na floresta virgem como um pioneiro: tive sede enquanto cortava árvores e fui para uma longínqua fonte no fundo de uma ravina. Uma sede tremenda antes de beber água e uma satisfação após bebê-la. "Ah, isto é língua, esta é uma língua-som [ongo, neologismo de Kôyama] que os seres humanos falam." Iko, iko, iko, iko, iko, iko! Gritei sozinho, iko, iko! Se os seres humanos falam uma língua-som, cada som guarda significado [grifo meu]. Devo pesquisar e percebê-lo. Meu sangue todo ficou quente como se olhos cegos houvessem visto a luz." (1970, 9-10)

Este episódio lembra a experiência $w$-a-t-e-r de Helen Keller, na medida em que ambos transmitem um momento de revelação na qual o laço imediato entre som, significado e referente é reconhecido através de um choque sensório inesperado. Mark Freeman interpreta o conhecido episódio de Keller como uma descoberta do "significado do significado mesmo" "De sensações sem palavras emergiu um pensamento genuíno" (Freeman, 1993, 56). Deste ponto em diante, a pequena Helen inferiu que tudo - não somente água - tinha um nome, e, mais importante, que todo nome tem escrita e som. "A aquisição da língua, ela percebeu, envolvia significantemente mais do que meramente nomes a uma palavra já significativa. Ao invés disso (...) a língua verdadeiramente criou um mundo" (ibid., 56). Freeman vê no episódio $w-a-t-e-r$ de Helen o nascimento dramático de si mesmo por meio da descoberta de um mundo cheio de significados construído pela língua. Se Helen compreende de $w-a-t-e-r$ a correspondência entre grafismo, som e referente, Kôyama extrapola de $i$-ko o escopo inteiro da correspondência léxica entre as duas línguas.

Pondo de lado a aparência, entretanto, uma diferença básica existe entre os dois episódios de revelação: a descoberta de Kôyama não se baseou na apreensão imediata de dados sensórios, mas numa lembrança tardia dela. Seu momento há muito esquecido numa densa floresta tornou-se retrospectivamente iluminado como um clarão crucial de "transformar-se em tupi" e assegurou-lhe uma ligação entre sua existência pessoal e um milênio de história anterior. Como ele sentiu, sensibilizou-se e atribuir sentido foi vital ao modo de construção de seu universo tupi. Reflexão e rememoração são concomitantes para ele. Ao escrever sobre tupi, não 
pretendia investigar o Outro; era antes um ato de escritura de sua própria história de um ponto de vista ancestral. Seu uso freqüente de cunhar estranhas expressões - "pesquisar-perceber" (kenkyû-kansei) e "significado-sensibilidade" (imi-kansei) - permitiram a Kôyama enfatizar a prioridade dos sentidos sobre a razão, da intuição sobre a lógica. Seu procedimento pode, portanto, ser compreendido como "ciência afetiva"

Kôyama defendia que seu conhecimento de nhem baseava-se em "cinqüenta anos de vida pioneira em florestas primitivas e vida colonial" $(1970,3)$. É verdade que passou cinqüenta anos no Brasil, mas viveu principalmente em cidades. Exagerando, se não inteiramente perjurando, seu passado autobiográfico como um pioneiro, ele inventa uma imagem de si mesmo designada a marcar uma afinidade irrefutável com os povos primitivos. É possível que Kôyama, inclusive, nunca tenha se encontrado com um índio, já que suas memórias não mencionam nenhuma ocasião tal.

\section{Da Coincidência à Correspondência}

Como é possível conectar estas duas línguas aparentemente incomensuráveis? Como o exemplo de iko demonstra, Kôyama foi capaz de associar, através do processo de tradução indireta (do tupi ao japonês através do português), uma sílaba japonesa com uma variedade de significados. Usou tal polissemia a fim de tornar densa a rede semântica, dedicando a maior parte de Investigação, volume $l$ a uma correspondência em forma de "dicionário" do tupi e do japonês. Mostrou que cada fonema japonês significa em tupi, pressupondo uma correspondência fonética correlativa entre as duas línguas, sem considerar qualquer desvio possível na transliteração de uma língua não-letrada para o português e depois ao japonês. Estava consciente de prováveis corrupções na transliteração alfabética pelos portugueses, que tenderam a julgar a partir de sua predisposição natural e a confundir /f/ e $/ \mathrm{h} /$, $/ \mathrm{j} /$ e $/ \mathrm{y} /$, etc. Pensava que os lingüistas japoneses, devido à sua afinidade racial com os tupis, talvez tivessem sido mais precisos que os portugueses em detectar e analisar o tupi falado (Kôyama, 1951, 15). Já que os livros portugueses eram as únicas fontes para dados lingüísticos encontráveis, Kôyama foi impossibilitado de descartar tais informações. Kôyama nunca confiou na lingüística ocidental, mas não pôde abandoná-la; ao invés disso, ele abusou dela. As linhas gerais do português funcionaram como um tipo de grade através da qual ele decifraria o código tupi-japonês. Em casos onde a literatura portuguesa não indicava explicitamente o significado tupi de certa sílaba japonesa, ele o inferia de outros exemplos usando a mesma sílaba.

Um exemplo do procedimento criptográfico de Kôyama para inventar significados de sílabas ocorre como se segue. Para estabelecer o significado de ho, ausente em livros portugueses (provavelmente porque o português não tem o $h$ aspirado), Kôyama primeiro coletou várias palavras tupis contendo ho- (ho-e, ho-i-to, ho-o-u), depois os sobrepôs, substraiu o resíduo $(-e,-i-t o \mathrm{e}-\mathrm{o}-\mathrm{u})$, e inferiu o denominador comum de $h o$. 
Este método de decifração foi facilitado por sua crença de que "cada som guarda em si significado", que lhe permitiram "cortar e colar" palavras aglutinantes a fim de adaptálas à semântica japonesa ${ }^{8}$.

A transcrição em ideogramas intensifica a polivalência de cada fonema porque usualmente ele representa mais de um significado. Além disso, um ideograma pode referir vários sons, enquanto um som pode ser escrito por vários ideogramas. Homônimos e sinônimos nas duas línguas também contribuíram para um número expansivo de combinações possíveis de sons e significados. Uma vez que a tabela de correspondência monossilábica foi estabelecida, tornou-se relativamente simples expandi-la para tabelas de di e trissílabas. O problema de Kôyama não era mais encontrar um significado, mas escolher aquele que seria mais apropriado. Já que a noção de corrupção fonética havia causado debates entre os tupinólogos brasileiros acerca das influências do português na pronúncia e transliteração do tupi, Kôyama, conscientemente ou não, estabeleceu uma regra $a d$ hoc de possibilidade de intercâmbios fonéticos.

\section{O Tupi como uma Lingua Ur}

Servindo-se do método analisado na seção anterior, Kôyama interpretou centenas de palavras em seu segundo livro de tupi, Investigação, Volume 1. Kôyama poderia ter aplicado este método para qualquer palavra existente, mas ele não o fez. Suas escolhas léxicas iluminam sua ideologia étnica e lingüística. Não importa quão escorregadia sua lógica possa parecer, suas escolhas foram sempre consistentes e coerentes. Excluiu sistematicamente palavras relacionadas, por exemplo, à civilização moderna e à sexualidade, e privilegiou topônimos, nomes próprios, e termos de história do Japão antigo (Kôyama, 1970, 125-39). Para Kôyama, a língua tupi compreendia o passado e a natureza.

Kôyama interpretou Kashiwara, o nome da cidade que entroniza o fundador mitológico do império japonês, da seguinte forma: Kashiwara = Koshiara ("passado" em tupi) $=k o$ (sustentar, crescer) $+\operatorname{shi}(\mathrm{luz})+\operatorname{ara}(\mathrm{sol})$. Tal leitura, portanto, corresponde a Amaterasu, a deidade japonesa do sol. Pelas mesmas evidências Kôyama reconstruiu o Japão arqueológico de acordo com o palimpsesto tupi: Jômon (a mais antiga civilização conhecida no Japão) $=J i$ (junto $)+y o$ (descendentes $)+m o($ fazer $)+m u$

8. Uma das regras da etimologia tupi para Theodoro Sampaio era "decompor o vocábulo etimologicamente restaurado por seus elementos aglutinados, sempre facilmente destacáveis, e colocá-los, dessa forma, em condição de serem traduzidos" $(1928,129)$. Este era exatamente o método de Kôyama, embora uma etimologia "cortar e colar" seja comum na lingüística fantástica. Assim como a maior parte dos filólogos comparativos de seu tempo, Sampaio achava que as línguas aglutinantes, como o tupi, eram menos evoluídas do que as flexionadas, como o português. 
(cooperação); Yamato (o primeiro reinado histórico conhecido) $=Y a$ (frutos) $+m a$ (local) + to (buraco, dobra). A lista continua .

A reinterpretação do Japão antigo por Kôyama encontra-se em harmonia com uma natureza exuberante e um povo generoso. Sua exegese não confronta igualmente uma língua com outra, mas submete a fala do antípoda de acordo com sua língua nativa. "É extremamente fácil", nota Marina Yaguello, "para um falante, ao inventar uma língua, criar seu vocabulário aplicando princípios neologísticos, mas é extremamente difícil escapar das convenções sintáticas de sua língua nativa" $(1991,98)$. O japonês foi, assim, o ponto de partida natural, e o destino final, de sua lingüística.

Para Kôyama, a relação entre o tupi e o japonês não era recíproca: as palavras japonesas podiam ser decifradas através da matriz tupi, mas tal não ocorria no caso inverso. Em outras palavras, o tupi proporcionava uma dimensão "paleo-semântica" que tinha sido acobertada por um milênio no processo de evolução (ou corrupção) lingüística do japonês. Se tupi é japonês-ur, então pode ser possivelmente mãe de todas as outras línguas? Para examinar esta possibilidade, Kôyama estendeu o método palimpsesto para os topônimos não-tupis do Brasil: Brasil $=$ Burajiru $=$ bura $($ cheio $)+$ jiru (juntar, ter, afundar, engolir); Paulista $=$ Paurisuta $+p a$ (pena) $+u$ (solo) $+r i$ (sobra, flutuação) $+s u$ (mudar) + ta (fogo, lenha).

O atlas tupi cobria o mundo todo e seus heróis, incluindo México, Andes, Mississipi, Kennedy, Sahara, Babilônia, Cleópatra, Roma, Platão, Cristóvão Colombo, Madagascar, Indonésia, Vietnã, e a Polinésia. Depois que esse topônimos foram estabelecidos, Kôyama compara a exegese de nomes comuns em chinês, coreano, ainu, malaio, sírio, português e inglês (Investigação, Volume l) e francês, espanhol, italiano, alemão, russo e hebraico (Investigação, Volume 2). Obviamente, os nomes e as palavras com os quais trabalha estão filtrados através da transliteração japonesa. Um exemplo - water - pode ser suficiente para se compreender este método: $M i z u$ (em japonês) $=m i$ (pouco, poucos, corpo, topo) $+z u$ (cair); Aguwa (em portugês) $=a$ (lugar, coisa, pessoa) $+g u$ (certeza) $+w a$ (engolir, redondo); Wa-a-ta-a ("water", em inglês) $=w a$ (algo para beber) $+a$ (expansão, cortar, atirar) $+t a$ (fogo) $+a$ (cortar, atirar). E assim prossegue.

9. A tendência de associar o tupi com um grande passado pode ser encontrada em artigos de outros japoneses que podem ter se inspirado em O Léxico Tupi. Por exemplo, Tadao Oka dá muitos exemplos ("Tupi-go to Man yô Kotoba" [A Língua Tupi e o Léxico Man yô], Paulista Shinbun, 10 de junho de 1959). Para ele, Shikishima (antigo nome apologético para o Japão) consistia de "shi (luz) + ki (descendente) + shima (brilho)". Em outras palavras, o Japão é celebrado já desde seus primórdios como "país de descendentes brilhantes" Certamente Oka e Kôyama se conheciam, e provavelmente foi o último que apontou a releitura de Man yôshû (língua man yô) em tupi. (Publicado no século VIII, Man'yôshû foi a primeira coleção poética conhecida do Japão). Kôyama também interpretou um poema do Man'yôshû em Investigação, Volume $l$ (137). Yoshio Ikeda, por sua vez, decifra as línguas do Egito antigo e de Okinawa de acordo com O Léxico Tupi ("Nazo no Tupi-go" [A Misteriosa Língua Tupi], Agosto-Novembro 1976, Paulista Shinbun), enquanto um artigo anônimo aplica uma grade tupi aos dialetos japoneses (Nippaku Mainiti Shinbun, 26 de fevereiro de 1963). É provável que a morte de Kôyama tenha desintegrado o interesse no tupi entre os glossófilos amadores. 
Kôyama articulou as combinações fonéticas de cada linguagem sem se preocupar com entonação, acento, e outras características (dessemantização), e depois os escreveu sob a forma japonesa. Esta "japonização" foi seguida por uma "tupinização", uma alocação de significado(s) da língua tupi obtido(s) através da semântica monossilábica para cada sílaba. Ao assim proceder, Kôyama inventou um sistema impecável de tradução: Língua X - transliteração japonesa - decifrador tupi-português - tradução para 0 japonês. Na medida em que nenhuma palavra era intraduzível, pois poderia ser transliterada em japonês, Kôyama não interpretou a composição semântica de palavras não-japonesas. Por exemplo, demonstrou como Wa-a-ta-a (water) pode ser reconstruído semanticamente, mas não explicita a seus leitores as implicações que subjazem "alguma coisa para beber + cortar/jogar + fogo + cortar/jogar"

Mas como operações fonéticas poderiam ser efetuadas se Kôyama tentasse compreender tupi (e outras línguas) sem a mediação escrita? Por vinte anos ele "pesquisou e sentiu" tupi uma hora por dia com sua secretária, e a língua existiu apenas em combinações valorizáveis de som e significado. Em outras palavras, Kôyama usou "matéria prima" para estimular fantasia lingüística, abrindo uma caixa secreta de tesouros para um simbolismo sonoro sob medida. Sua cunhagem do termo ongo (som-língua) revelou seu foco no som e sua separação da relação convencional entre som e significado. Enquanto Kôyama dizia a seus leitores pouco sobre o significado de sua "etimologia universal", é certo que não estava consciente de que suas preocupações estavam mudando, partindo do enfoque da origem da língua japonesa para o das línguas mais gerais.

\section{Simbolismo Sonoro e Hipótese Monogenética}

Do ponto de vista lingüístico, esta mudança significou muito mais do que Kôyama havia pensado. Seu ponto de partido, O Léxico Tupi, consiste em um processo ortodoxo de tradução lexical: transferência semântica de palavras de um sistema lingüístico para outro. Pressupõe dois (ou três) sistemas lingüísticos distintos que podem ser relacionados através da transparência de correspondência semântica (ou pelo menos de aproximação). Essa relação entre o significado e o significante dentro de cada sistema e entre sistemas é tido como arbitrário de acordo com os lingüistas modernos.

Investigação, Volume 1 pressupõe uma hipótese totalmente diferente: embora a relação entre o significado e o significante dentro de cada sistema seja arbitrário, aquela entre sistemas é inegavelmente motivada (não arbitrária). A língua, na visão de Kôyama, é mimética e congruente assim como sinestésica. Sua epifania iko é exemplar porque ele encontra essas duas sílabas em congruência com o sentido da sede em sua memória. Ele admite o princípio da analogia e da mimese fonética no proto-japonês-tupi. Se o processo de tradução ortodoxa se ancora na suposta identidade semântica de lexemas diferentes (unidades léxicas), o palimsesto que Kôyama coloca identifica fonemas similares (unidades fonéticas), designando significados diferentes em línguas diferentes. É apenas uma decisão de qual enfatizar - significado ou som - que faz a diferença. $O$ que interessa em Investigação, Volume 1 é a congruência não entre o significado e o 
significante em japonês ou em tupi mas, antes, a congruência entre os significados nessas duas línguas. Enquanto identifica uma unidade semântica com uma fonética, Kôyama admite uma expressão motivada de substância fonética e nega a articulação dupla enfatizada pela lingǘstica estrutural. Sua idéia se aproxima do simbolismo sonoro: o significado é percebido de modo intrínseco no som (Dogana, 1983, 58; veja-se também Todorov, 1972). Diferente do simbolismo sonoro num sistema monolingüístico, que em geral busca afinidade entre o som lingüístico e a natureza das coisas que ele denota (p.e., onomatopéia, percepção colorística, ou expressão emotiva de vogais e consoantes), Kôyama aplica-a a uma interlingüística na qual a relação entre o significado e o significante em sua língua materna é tomada como inquestionavelmente natural, enquanto tal relação em línguas estrangeiras é suscetível de uma construção fantástica. Kôyama localiza no japonês e no tupi o "resíduo de uma forma expressiva arcaica" (Dogana, 1983, 288).

Quando ele extrapola o princípio de congruência e analogia para outras línguas, alude a uma hipótese monogenética ou a idéia de "derivação de todas as línguas a partir de apenas uma língua-mãe" (Eco, 1994, 71). Através da história intelectual européia, de acordo com Eco, certas línguas santificadas foram colocadas repetidamente como as matrizes das outras línguas. $O$ hebreu e o sânscrito não eram candidatos mais verossímeis do que o celta ou o basco (veja-se Bergheaud, 1985; Yaguello, 1991, 21; Sarmiento, 1985). A questão da origem sempre se manteve dependente da imaginação mítico-política. Por exemplo, Francisco Adolfo de Varnhagen (1876), historiador oficial do Brasil após a independência, explorou a inovadora teoria de que o tupi e todas as línguas antigas haviam derivado do turan, uma tribo às margens do Nilo. A implicação política de tal surpreendente teoria resultava em que os índios brasileiros não mais seriam criaturas primitivas, mas descendentes de uma civilização clássica ${ }^{10}$.

10. É intrigante comparar Kôyama e Varnhagen em termos da teoria monogenética do tupi. O último descobriu as palavras em tupi rha, ioh e siu, designados igualmente no Egito antigo como o sol, a lua e as estrelas, respectivamente (Varnhagen, 1876, 27-28, 137-38). A deidade maior dos tupis, Tupã, deus do trovão, mantém em si mesmo uma ressonância com o egípcio To-Pan (Pan do país). Este "Pan" pode ser também chamado "Khen", o que corresponde a Júpiter, deus do trovão (ibid., 62-63). De acordo com Varnhagen, os tupis emigraram do Egito durante os séculos V e VI a.C. Configurando-se como a mais antiga das migrações, eles viajaram aos mais longinquos lugares, até ao sul do Brasil. Como resultado, o tupi contém as mais antigas línguas como as grega, assíria, fenícia, e assim por diante. Ainda, Varnhagen encontrou correspondência lexical com o mongol, o tártaro, o basco, o árabe, o húngaro, o malaio e algumas outras línguas. A similaridade com a abordagem de Kôyama é óbvia. Curiosamente, Varnhagen nunca concordou com a conexão tupi com as línguas da Europa ocidental. Sua filologia comparada enfatiza culturas exóticas e/ou antigas. Varnhagen também analisou a significação do tupi como "ancestral" em detalhes (ibid., 4), segundo o qual o tupi é o exótico Adam, originário do Egito. Varnhagen tinha a teoria de que a influência lingüística era concomitante com a conquista; na extensão em que o império egípcio (turaniano) aumentou, sua língua afetou as semíticas. O conhecimento de Varnhagen sobre o antigo Egito tomou claramente como empréstimo o orientalismo pós-napoleônico. (Sobre o impacto da teoria turaninana da identidade cultural árabebrasileira, veja-se Lesser, 1999, 43). A língua tupi foi também tema de filologia comparada por Lucien Adam, um intelectual francês de fim-de-século (1968 [1896]), que implica num interesse intermitente nos povos indígenas brasileiros na França desde Jean de Léry. 
Para Kôyama, o tupi representou tanto o ur-japonês quanto o ur-brasileiro. $\mathrm{O}$ tupi permitiu que os japoneses no Brasil celebrassem o mito da miscigenação racial pacífica, fortificando assim uma brasilianidade autêntica dos japoneses, um grupo excluído do mito de fundação. Enquanto $O$ Léxico Tupi tinha a intenção implícita de estabelecer pazes dentro de uma comunidade dividida - dirigia-se textualmente a um grupo intra-étnico - as Investigações são explicitamente concebidas para afirmar o mito racial brasileiro. A referência ao tupi foi, para o poeta cego, uma "ficção de fundação" (Sommer, 1991) que aceitava um grupo minoritário. Esta ficção não tinha como objetivo construir uma nova contra-narrativa que subvertesse potencialmente a narrativa da sociedade dominante, mas antes, participava da ordem hegemônica. Não tinha por objetivo uma separação étnica, mas uma integração social. A admiração notável de Kôyama pela democracia racial no Brasil é evidente no parágrafo final de Investigação, Volume 2: "No meio do século XIX, uma língua universal, esperanto, inventado por Zamenhof na Europa, tornou-se popular. Mas parece-me que é o Brasil (ao invés do Esperanto) que está percebendo a idéia universal da igualdade dos seres humanos porque esse país não discrimina nenhum imigrante, de nenhum lugar do mundo. Suponho que em alguns séculos as línguas étnicas de todo o mundo reconhecerão o um-som-um-significado-próprio da língua-som tupi, como investigados nos livros portugueses" (35). Para Kôyama, seria apenas quando todos os povos do mundo "sentissem" o simbolismo sonoro tupi oculto em todas as línguas, que se tornariam capazes de se comunicarem entre si. Como os tupis do passado, o mundo se tornaria verdadeiramente pacífico.

\section{Conclusão: Lingüistica Fantástica e a Construção da Identidade}

A origem das línguas, muito depois de seu exílio dos jardins da Lingüística, ainda encanta numerosos cientistas populares. Tais teorias, entretanto, encontram um lugar legítimo em "lingüísticas fantásticas" ou "todos os discursos e todas as práticas que a constituição gradual de uma disciplina oficial marginalizou e algumas vezes até excluiu do campo científico" (Auroux et al., 1985, 11). Com a exceção de duas questões das mais abnegadas - a origem da língua e a língua universal -, glossolalia, lapsos, língua não comunicativa, e língua ficcional encontram-se entre os objetos privilegiados desta disciplina. $\mathrm{O}$ que se observa não repousa num valor-verdade objetivo, mas na singularidade do autor (ibid., 18). Encontra-se condicionado pela história, ou mais precisamente, pelas margens da história. O que se encontra na lingüística fantástica não é negligência ou abandono da ciência moderna, mas seu abuso e deturpação ${ }^{11}$

A lingüística fantástica ignora a ortodoxia da lingüística. Eles "recusam a linearidade do significado, confundem os eixos paradigmático e sintagmático, articu-

11. Sobre a busca "não-fantástica" (científica) pela origem da língua, veja-se Lamb e Mitchell, 1991; Miller, 1971; Ruhlen, 1994. 
lam a língua de uma única maneira, atribuem ao significado exegeses infinitas, etc." e tendem a conectar a língua imaginária a "elementos extrínsecos tais como localização, sexo ou gênio dos povos" (Aroux et al., 1985, 23). A tarefa da lingüística fantástica é localizar os glossófilos no amplo contexto do conhecimento, questionando como e por que eles fracassaram na construção de autênticos objetos da lingüística moderna. Por estarem fora de lugar eles iluminam os limites do discurso científico, borrando e ultrapassando as fronteiras entre ciência e fantasia. Mesmo que a imaginação lingüística muitas vezes refira o passado (mito da origem da língua) ou o futuro (utopia de uma língua universal), as questões levantadas indicam condições críticas de suas línguas atuais. Todas essas características operam claramente nas análises de Kôyama.

Kôyama negligenciava a lingüística moderna, mas, ao mesmo tempo, suas idéias estavam profundamente embasadas nas condições históricas nas quais viveu. Construiu um labirinto cheio de confusão entre lógica e intuição, assunção e fato, memória pessoal e descrição objetiva. Seus textos não são tanto ciência degenerada quanto são uma narrativa enraizada em experiência pessoal e sentimento coletivo. A semelhança fisica entre os tupis e os japoneses era apenas um sinal visível, já que Kôyama tentou demonstrar como a afinidade lingüística era prova de sua contraparte genética. Regras ad hoc foram acrescentadas quando os resultados contradiziam o fantasma da prioridade absoluta. Tais invenções narrativas pretendiam salvar a fantasia geralmente oculta, como se opera nos contos folclóricos. Assim, a busca de significado dos nomes de Kôyama assemelha-se mais com a etimologia folclórica do que com a lingüística. Atribuindo significação tupi a várias palavras de várias línguas, ele nomeou o mundo, observando-o com olhos dos tupis, ouvindo a língua com ouvidos dos tupis, e sentindo o mundo como os tupis o "sentiam" Assim fazendo, tentou quebrar os limites da língua e os limites do mundo vivido.

A incomensurabilidade da língua é naturalmente recíproca, mas influencia de modo desigual as vidas de anfitriões e convidados. A profissão inicial de Kôyama como intérprete o tornou agudamente cônscio da posição estrangeira de sua língua nativa em seu segundo lar. Reconhecer sua língua nativa como estrangeira é sentir sua língua presa. Uma maneira de escapar da prisão da língua é "dominar" a língua do outro, mas um outro modo mais radical de fazê-lo (pelo menos em termos ideológicos) é insistir que mesmo os brasileiros que falam português, monolíngües como os imigrantes, estão aprisionados, a menos que notem que nenhum língua se encontra igualmente distante da língua-ur do tupi.

Essa incomensurabilidade das duas línguas sofreu um curto-circuito pela invenção e intervenção de um "terceiro espaço", um espaço arcaico que permitiu qualquer investimento semântico, qualquer referência imaginária, qualquer fantasia surreal. Este espaço, concebido como tupi por Kôyama, é vazio o suficiente para ser preenchido com significados arbitrários e interpretações, já que se encontra já pleno de simbolismo nacional e clichês exóticos.

Kôyama estava procurando por uma narrativa que redimisse a marginalidade patente de sua comunidade com respeito à demografia, cultura e língua. Não ignorava 
a posição subalterna de sua língua nativa no Brasil e a influência limitada de seu trabalho. Publicar um trabalho em japonês no Brasil não poderia ajudar, mas continha a "dupla articulação" da friç̧ão nacional/étnica. Desvelando a língua nativa, a geração issei ansiava pela origem perdida que havia inequivocamente resistido ao monolingüismo do Brasil. Kôyama não alterou a incompatibilidade das duas línguas nem a visão dos brasileiros sobre os japoneses. Mesmo assim, seus escritos não foram inexpressivos. Ao contrário, Kôyama tentou se tornar brasileiro através do uso estratégico da imaginação mítica e da semelhança física. Longe de ser uma excentricidade de um recluso cego ou um absurdo lingüístico, seu universo tupi-nipo-brasileiro articula condições sociopolíticas, afetivas e ideológicas da comunidade nikkei. É "fantasia verdadeira" imersa na consciência mítico-histórica de um grupo de minorias.

\section{Bibliografia}

ADAM, Lucien.1968 [1896]. Matériaux pour Servir à l'Etablissement d'une Grammaire Comparé des Dialectes de la Famille Tupi [Material para Servir ao Estabelecimento de uma Gramática Comparada dos Dialetos da Família Tupi]. Paris: J. Maisonneuve.

ANDRADE, Mário de. 1991. Aspectos da Música Brasileira. Belo Horizonte, Brazil: Villa Rica.

ANDREWS, George Reid. 1991. Blacks and Whites in São Paulo, Brazil 1888-1988 [Pretos e Brancos em São Paulo, Brasil, 1888-1988]. Madison: University of Wisconsin Press.

AUROUX, Sylvain, CHEVALIER, Jean-Claude, JACQUES-CHAQUI, Nicole \& MARCHELLO-NIZIA, Christine. 1985. La Linguistique Fantastique [A Lingüística Fantástica]. Paris: Clims-Denoël.

AYROSA, Plinio. 1933. Primeiras Noções de Tupi. São Paulo: Centro do Professorado Paulista.

1967. Estudos Tupinológicos. São Paulo: Instituto de Estudos brasileiros.

BASTIGE, Roger \& FERNANDES, Florestan. 1959. Brancos e Negros em São Paulo. São Paulo: Companhia Editora Nacional.

BERGHEAUD, Patrice. 1985. Le Mirage Celtique: Antiquaires et Linguistes en Grande-Bretagne au XVIIIe Siècle [A Miragem Céltica: Antiquários e Lingüistas na Grã-Bretanha no Século XVIII]. In La Linguistique Fantastique [A Lingüística Fantástica], editado por Sylvain Auroux et al., 51-60. Paris: Clims-Denoël.

BURNS, E. Bradford. 1968. Nationalism in Brazil: A Historical Survey [Nacionalismo no Brasil: Uma Visão Histórica]. New York: Frederick A. Praeger.

CHERMONT DE MIRANDA, Vicente. 1946. Estudos sôbre o Nhêengatú. Rio de Janeiro: Imprensa Nacional.

COSTA, Angyone. Introdução à Arqueologia Brasileira: Etnografia e História. São Paulo: Companhia Editora Nacional. 
DIETRICH, Wolf. 1990. More Evidence for an Internal Classification of Tupi-Guarani Languages [Mais Evidências para uma Classificação Interna das Línguas TupiGuarani]. Berlin: Gebr. Mann Verlag.

DOGANA, Fernando. 1983. Suono e Senso: Fondamenti Teorici ed Empirici del Simbolismo Fonético [Som e Sentido: Fundamentos Teóricos e Empíricos do Simbolismo Fonético]. Milan: Franco Angeli.

ECO, Umberto. 1994. La Búsqueda de la Lengua Perfecta [A Busca da Língua Perfeita]. Barcelona: Crítica.

FERNANDES, Florestan. 1972. O Negro no Mundo dos Brancos. São Paulo: Difusão Européia do Livro.

FONTAINE, Pierre-Michel, ed. 1985. Race, Class, and Power in Brazil [Raça, Classe e Poder no Brasil]. Los Angeles: Center for Afro-American Studies, University of California.

FREEMAN, Mark. 1993. Rewriting the Self: History, Memory, Narrative [Reescrevendo-se a Si-mesmo: História, Memória, Narrativa]. London: Routledge.

FREITAS, Affonso Antônio de. 1936. Vocabulário Nheengatú. São Paulo: Companhia Editora Nacional.

GEIPEL, John. 1993. Brazil's Unforked Tongue [Línguas Não-Derivadas do Brasil] History Today [História Hoje] 43: 11-14.

GUASCH, Padre Antonio. 1961. Diccionario Castellano-Guarani y GuaraniCastellano. Seville: Ediciones Loyola.

HABERLY, David T. 1983. Three Sad Races: Racial Identity and National Consciousness in Brazilian Literature [Três Tristes Raças: Identidade Racial e Consciência Nacional na Literatura Brasileira]. Cambridge: Cambridge University Press. HELLWIG, David J., ed. 1992. African-American Reflections on Brazil's Racial Paradise [Reflexões Afro-Americanas no Paraíso Racial do Brasil]. Filadélfia: Temple University Press.

HOSOKAWA, Shuhei. 1999. Nationalizing Chô-Chô-San: The Signification of "Butterfly Singers" in a Japanese-Brazilian Community [Nacionalizando Chôchôsan: A Significação das "Cantoras Borboletas" numa Comunidade Nipo-Brasileira]. Japanese Studies [Estudos Japoneses] 19, no. 3: 253-68.

KÔYAMA, Rokurô. 1951. Tupi Tango Shû [O Léxico Tupi]. São Paulo: Teikoku Shoin. 1970. Tupi Ongo Niemu no Gogen Imide Jinrui Ongo Kôsei Ichion Ichion o Imi Kansei Kenkyû [Investigação de Significado-Sentido de Cada sílaba na Composição da Língua Verbal Humana Através do Significado Original da Língua Tupi Nhem], vol. 1. São Paulo: edição particular.

1973. Tupi Ongu Niemu no Gogen Imide Jinrui Ongo Kôsei Ichion Ichion o Imi Kansei Kenkyû [Investigação de Significado-Sentido de Cada Sílaba na Composição da Língua Verbal Humana Através do Significado Original da Língua Tupi Nhem], vol. 2. São Paulo: edição particular.

1976. Kôyama Rokurô Kaisôroku [Memórias de Rokurô Kôyama]. São Paulo: Centro de Estudos Nipo-Brasileiros. 
LAMB, Sydney M. \& MITCHELL, E. Douglas, eds. 1991. Sprung from Some Common Source: Investigations into the Prehistory of Languages [Provindos da Mesma Fonte: Investigações sobre a Pré-História das Línguas]. Palo Alto, Califórnia: Stanford University Press.

LESSER, Jeffrey. 1999. Negotiating National Identity: Immigrants, Minorities, and the Struggle for Ethnicity in Brazil [Negociando a Identidade Nacional: Imigrantes, Minorias e a Luta pela Etnicidade no Brasil]. Durham, N.C.: Duke University Press.

LUÍS, Pedro \& A PAREDE. 1999. "Brasileiro em Tóquio." É Tudo Real. WPCR10445.

MILLER, Roy Andrew. 1971. Japanese and the Other Altaic Languages [O Japonês e Outras Línguas Altaicas]. Chicago: University of Chicago Press.

1977. The Japanese Language in Contemporary Japan: Some Sociolinguistic Observations [A Língua Japonesa no Japão Contemporâneo: Algumas Observações Sociolingüísticas]. Washington, D.C.: Hoover Institution.

1980. Origins of the Japanese Language: Lectures in Japan during the Academic Year 1977 [Origens da Língua Japonesa: Palestras no Japão no Ano Acadêmico de 1977]. Seattle: University of Washington Press.

MURAI, Osamu. 1992. Nantô Ideology no Hassei [O Nascimento da Ideologia das Ilhas do Sul]. Tokyo: Fukutake Shoten.

1993. Kigen to Seifuku [Origens e Conquista]. Hihyô Kûkan II: 156-61.

NEIVA, Arthur. 1940. Estudos da Lingua Nacional, São Paulo: Companhia Editora Nacional.

RIVET, Paul. 1957. Les Origines de l'Homme Américain [As Origens do Homem Americano]. Paris: Gallimard.

RUHLEN, Merritt. 1994. The Origin of Language: Tracing the Evolution of the Mother Tongue [A Origem da Língua: Traçando a Evolução da Língua Materna]. New York: John Wiley and Sons.

SAMPAIO, Theodoro. 1928. O Tupi na Geographia Nacional. Bahia: Secção Graphica da Escola de Aprendizes Artífices.

SARMIENTO, Ramon. 1985. Le Basque et la Racine du Savoir [O Basco e a Razão do Saber]. In La Linguistique Fantastique [A Lingüística Fantástica], editado por Sylvain Aurox et al., 61-73. Paris: Clims-Denoël.

SKIDMORE, Thomas E. 1993 [1973]. Black into White: Race and Nationality in Brazilian Thought [Preto no Branco: Raça e Nacionalidade no Pensamento Brasileiro]. Durham, N.C.: Duke University Press.

SOMMER, Doris. 1991. Foundational Fictions: The Nacional Romances of Latin America [Fiç̧ões de Fundação: O Romance Nacional da América Latina]. Berkeley: University of California Press.

TANAKA, Katsuhiko. 1991. Gengo Kara Mita Minzoku to Kokka [Etnicidade e Nação sob o Prisma da Língua]. Tokyo: Iwanami. 
TODOROV, Tzvetan. 1972. Le Sens des Sons [O Significado dos Sons]. Poétique II: 273-308.

VARNHAGEN, Francisco Adolpho de. 1876. L'origine Touranienne dês Américains Tupis-Caribes et dês Anciens Egyptiens Mondré Principalement par La Philologie Comparée: Et Notice d'une Emigration em Amérique Effectuée à Travers l'Atlantique Plusieurs Siècles avant notre Ere [A Origem turiana dos tupis e caribenhos americanos e os antigos egípcios mostrada principalmente pela Filologia Comparada: e notícias de um imigrante na América através do Atlântico muitos séculos antes de nossa era]. Viena: Librairie I. et R. de Faesy and Frick.

WINANT, Howard. 1994. Racial Conditions: Politics, Theory, Comparision [Condições Raciais: Política, Teoria, Comparação]. Minneapolis: University of Minnesota Press.

WITTGESNSTEIN, Ludwig, 1997. Philosophical Investigations [Investigações Filosóficas]. Trad. G. E. M. Anscombe. Oxford: Blackwell, I, §19.

YAGUELLO, Marina, 1991. Lunatic Lovers of Language: Imaginary Languages and Their Inventors [Amantes Lunáticos das Línguas: Línguas Imaginárias e Seus Inventores]. London: Athlone Press.

(Tradução: Madalena Natsuko Hashimoto Cordaro - FFLCH/USP) 
